\title{
Avaliação do potencial de melhoria dos processos de empresas de transporte rodoviário urbano: estudo de caso em três empresas de Porto Alegre - RS
}

\section{Miriam Borchardt}

Engenharia de Produção - Universidade do Vale do Rio dos Sinos, UNISINOS

Giancarlo Medeiros Pereira

Engenharia de Produção - Universidade do Vale do Rio dos Sinos, UNISINOS

\author{
Antônio Sérgio Coelho \\ Engenharia de Produção e Sistemas - Universidade Federal de Santa Catarina, UFSC
}

RESUMO: Este artigo apresenta os dados obtidos a partir de estudos de casos em três empresas de transporte coletivo rodoviário urbano de Porto Alegre. O objetivo é identificar o potencial de melhoria dos processos destas organizações. Para tanto, foi desenvolvido um instrumento de diagnóstico que considera a realidade do setor de transporte por ônibus nesta cidade e sistemas de gestão baseados na melhoria dos processos, tais como: critérios de excelência do Prêmio ANTP de Qualidade, os princípios da Mentalidade Enxuta e do Lean Management. O conhecimento do cliente e de suas expectativas é um fator considerado relevante pelas três organizações estudadas. A integração da cadeia de valor do sistema de transporte é um dos parâmetros avaliados que apresenta o maior potencial de melhoria.

ABSTRACT: This article presents the data gotten from multiple cases studies developed in three companies of urban road public transport of Porto Alegre. This work proposes, as a target, identifying the potential of process improvement in these organizations. A diagnostic tool was devised using the characteristics of the transportation system by bus in this city and using the theoretical framework of systems of management linked with the improvement of the processes, such as: the Criteria of Excellence of the Public Transportation Quality Award, the Lean Thinking principles and the Lean Management concepts. All the three companies think that the knowledge about the customers and their expectation are relevant and representative in order to improve the companies' process. The value chain is the main parameter with a great potential of improvement.

\section{INTRODUÇÃO}

$\mathrm{O}$ aumento do tráfego torna o transporte público mais lento e menos confiável, reduzindo sua demanda e receita. Em decorrência do exposto, são necessários mais veículos para prestar o mesmo serviço, fato esse que se reflete em um significativo aumento de custos. A associação entre os elementos descritos prejudica os usuários cativos do transporte público, bem como desestimula os usuários potenciais do transporte coletivo. Nesse contexto, aqueles que podem transferem-se para o transporte particular, aumentando o congestionamento e alimentando o círculo vicioso (ANTP, 1999).

A Figura 1 ilustra a tendência de queda de passageiros transportados pelo sistema de ônibus urbano nas principais capitais do Brasil. Conforme a NTU (2004), o número de passageiros transportados por mês, nas capitais mencionadas na Figura 1, caiu de 406 milhões para 267 milhões entre 1994 e 2004 (dados relativos ao transporte regular, não se considerando o transporte clandestino).

Uma vez que a melhoria do transporte coletivo traz benefícios para toda a sociedade, e, em especial, para as camadas menos favorecidas, cumpre questionar as ações que possam melhorar o atual quadro do setor. Desta forma, o presente trabalho analisará as empresas de transporte por ônibus objetivando identificar alternativas operacionais que possam melhorar os resultados dessas organizações frente ao atual cenário em que se encontra o setor.

Uma alternativa a ser considerada pelas empresas de transporte coletivo rodoviário urbano é a adoção de princípios e técnicas capazes de diminuir as perdas e, conseqüentemente, aumentar os ganhos das empresas através de uma maior eficiência do fluxo de valor, estruturado com base nos requisitos do cliente. A questão de pesquisa advinda da presente proposta é: como as empresas de transporte coletivo 


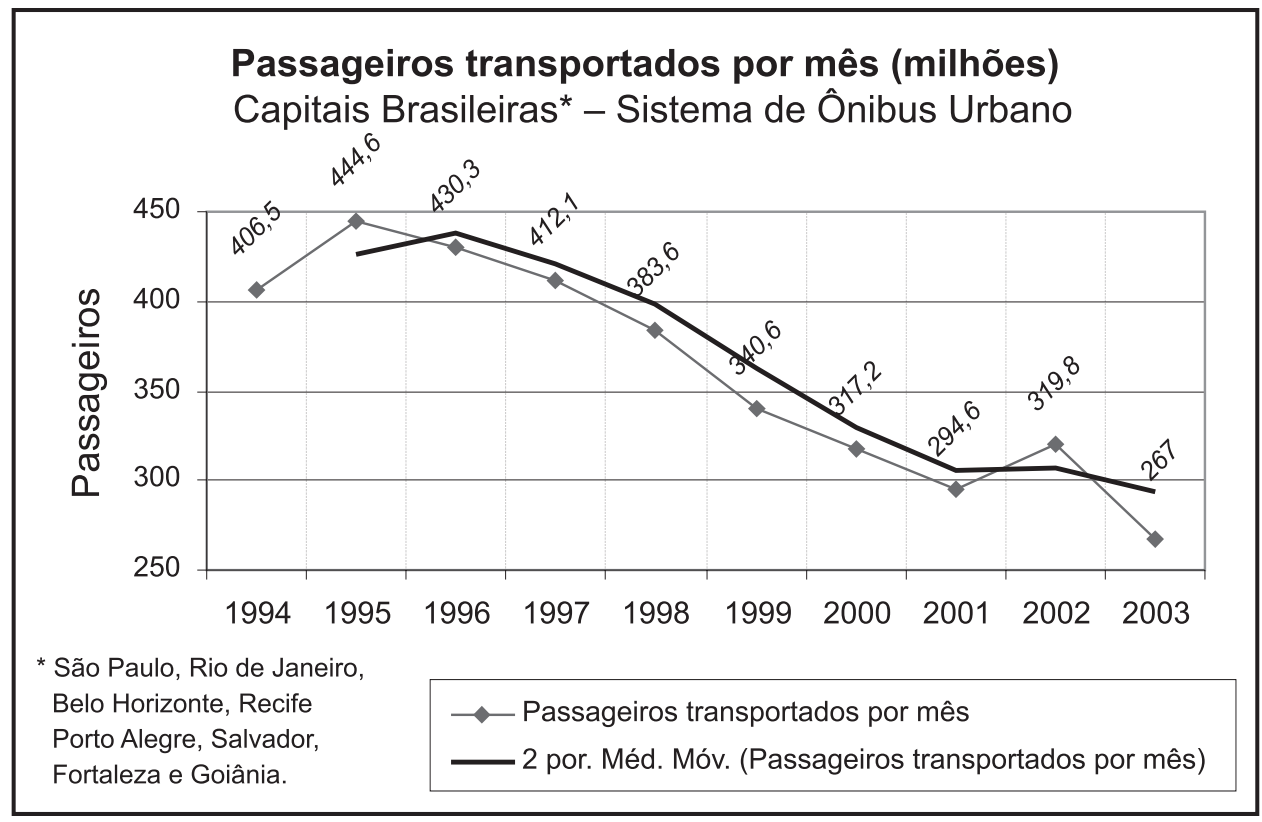

Figura 1: Passageiros transportados por mês. Fonte: NTU (2004)
Apresentam-se, a seguir, as características do transporte coletivo rodoviário urbano em Porto Alegre, RS - 1ocal onde se concentraram as pesquisas. Segue-se com o referencial teórico que dará sustentação ao desenvolvimento do instrumento gerencial de avaliação. Discute-se, em seguida, o delineamento da pesquisa, detalhando-se o método utilizado. A seguir, apresenta-se a estrutura do instrumento gerencial e os três casos de aplicação do mesmo em empresas de Porto Alegre. Finalizando, traçam-se as considerações finais e conclusões. rodoviário urbano podem identificar os principais processos a serem melhorados, de modo a reduzir perdas e, conseqüentemente, aumentar ganhos?

A busca pela eliminação das perdas nos processos das organizações leva ao que Henderson e Larco (2002) e Womack e Jones (1998) definiram como "sistema enxuto". Um sistema enxuto fornece para as pessoas de todos os níveis da organização as ferramentas e a forma de pensar sistemicamente, o modo de eliminar as perdas, através da concepção e projeto de produto e processo, da melhoria das atividades, da melhoria entre as conexões entre processos internos e externos, e do fluxo.

Dentre as teorias que conduzem uma organização a melhorar seus processos e diminuir as perdas, destacam-se as apresentadas por Antunes Jr. (1998): o Sistema Toyota de Produção (STP), as propostas de qualidade na gestão sugeridas a partir de Deming, Juran, Crosby, Feigenbaum, Ishikawa e a reengenharia de negócios e de processos. Womack e Jones (1998) introduziram a Mentalidade Enxuta e Jackson e Jones (1996), o Lean Management; ambos com abordagem centrada em melhorar processos e diminuir perdas.

Objetivando colaborar para a melhoria da qualidade do transporte coletivo e à luz do arcabouço teórico apresentado, esse trabalho propõe desenvolver um instrumento gerencial para avaliação do potencial de melhoria dos processos de organizações de transporte coletivo rodoviário urbano. Dessa forma, será possível para as empresas estabelecerem as técnicas e ferramentas apropriadas para sua realidade e priorizarem as ações onde o potencial de melhorias dos processos é maior ou mais urgente.

\section{CARACTERÍSTICAS DO TRANSPORTE COLETIVO DE PORTO ALEGRE}

Costa et al. (2001) descrevem que, em Porto Alegre, o transporte coletivo por ônibus é regulamentado desde 1928, funcionando com permissão por linha e por empresa.

Em Porto Alegre existem quinze empresas de transporte coletivo por ônibus, sendo uma pública e as demais privadas. O sistema de transporte por ônibus está organizado, desde 1992, em grupos de empresas - os consórcios. Segundo EPTC (2004), o consórcio Conorte é formado por três empresas que juntas totalizam 416 veículos e atendem a bacia geográfica norte. $O$ consórcio Unibus tem 370 veículos, com seis empresas associadas que atendem a bacia geográfica leste. O consórcio STS é formado por cinco empresas que atuam na bacia geográfica sul e totalizam 447 veículos. As linhas transversais são atendidas por uma empresa pública, a Carris, com 323 veículos.

O equilíbrio econômico-financeiro do sistema, segundo Azambuja (2002), foi preservado pela adoção de um mecanismo de compensação financeira, mediante o qual as empresas superavitárias, por possuírem linhas com custos internos inferiores à média do sistema, repassam parte da receita às empresas operando em situação deficitária. A Câmara de Compensação Tarifária (CCT) é responsável pelos repasses entre as bacias geográficas, incluindo a empresa pública (Carris). Os consórcios, por sua vez, administram a compensação interna entre as empresas, com base no percentual de custos de cada uma.

O STS (2004) apresenta como vantagens dos consórcios: ordenamento dos horários de todas as 
linhas de uma determinada bacia geográfica da cidade; possibilidade da criação de linhas rápidas, diretas e semi-diretas; diminuição dos tempos de viagens; maior flexibilidade para suprir horários com maior demanda; e, melhor qualidade na prestação do serviço.

O sistema de transporte coletivo em Porto Alegre é regulamentado por um Órgão Gestor, a Empresa Pública de Transporte e Circulação - EPTC. A EPTC estabelece os critérios de produção, através de tabelas horárias e requisitos de qualidade do serviço prestado. Segundo EPTC (2004), estes requisitos são aferidos periodicamente junto aos usuários do serviço através de pesquisas de informação (qualitativas e quantitativas). Cabem às empresas o gerenciamento para que se atinjam estes requisitos e se cumpram os objetivos de produção.

A EPTC (2004) destaca que em Porto Alegre o transporte clandestino ou irregular praticamente inexiste. A queda no número de passageiros transportado pelo sistema foi de 13,89\% entre 1998 e 2003 .

\section{REFERENCIAL TEÓRICO}

Diversas opções teóricas, técnicas e ferramentas, casos e aplicações, cujos princípios convergem para a idéia central de eliminação de perdas e melhoria dos processos das organizações, estão disponíveis na literatura Ballard, 2003; Cerra e Bonadio, 2000; Cunningham et al., 2000; Cypriani e Guedes, 2002;
Fullerton et al., 2003; Henderson e Larco, 2002; Johnston et al., 2001; Nilsson et al., 2003; Sánchez e Pérez, 2001; Kaynak, 2003.

Segundo Borchardt (2005), as abordagens relativas aos sistemas de gestão da qualidade baseados nos Critérios de Excelência, a Mentalidade Enxuta e o Lean Management são apropriadas aos propósitos desse trabalho em função de buscarem sistematizar a implementação de sistemas enxutos e pela capacidade de aplicação em empresas de serviços. Estas abordagens foram, então, selecionadas para a formação da base conceitual desta investigação. A seguir, detalham-se cada uma delas.

\subsection{Critérios de Excelência do Prêmio ANTP de Qualidade 2005}

Os critérios de excelência têm se consolidado como referência nas organizações. $\mathrm{O}$ mais conhecido no Brasil é o sistema de gestão baseado nos Critérios de Excelência do Prêmio Nacional da Qualidade (PNQ). Os critérios de excelência sustentam a idéia de que todos os processos da organização estão integrados e que o desempenho global depende da atuação de cada área, da estratégia e do modo como contribuem para os resultados.

Com base no PNQ, foi criado em 1995, por decisão da Comissão de Qualidade e Produtividade da ANTP (Associação Nacional dos Transportadores de Passageiros), o Prêmio ANTP de Qualidade. O

Quadro 1: Critérios do Prêmio ANTP de Qualidade 2005

\begin{tabular}{|l|l|}
\hline \multicolumn{1}{|c|}{ Critério } & \multicolumn{1}{|c|}{ Características } \\
\hline 1. Liderança & $\begin{array}{l}\text { Examina como a alta direção estabelece e dissemina os valores organizacionais, as diretrizes } \\
\text { e expectativas de desempenho, o foco nos clientes e nas demais partes interessadas. }\end{array}$ \\
\hline 2. Planejamento estratégico & Examina como a organização define suas estratégias e as desdobra em planos de ação. \\
\hline $\begin{array}{l}\text { 3. Foco nos clientes e na } \\
\text { sociedade }\end{array}$ & $\begin{array}{l}\text { Examina como a organização identifica e se antecipa aos requisitos, expectativas e preferên- } \\
\text { cias de seus clientes e da sociedade. }\end{array}$ \\
\hline $\begin{array}{l}\text { 4. Mensuração, análise e } \\
\text { gestão do conhecimento }\end{array}$ & $\begin{array}{l}\text { Examina como a organização seleciona, obtém, analisa e melhora seus dados, informações } \\
\text { e conhecimentos. }\end{array}$ \\
\hline $\begin{array}{l}\text { 5.Gestão de pessoas } \\
\text { 6.Gestão de processos }\end{array}$ & $\begin{array}{l}\text { Examina como são proporcionadas condições para o desenvolvimento e utilização plena do } \\
\text { potencial das pessoas que compõem a força de trabalho. }\end{array}$ \\
\hline $\begin{array}{l}\text { 7. Resultado da organização } \\
\text { dos serviços/produtos com foco no cliente, a produção dos serviços, os processos de apoio e } \\
\text { aqueles relacionados aos fornecedores, em todos os setores e unidades. }\end{array}$ & $\begin{array}{l}\text { Examina a evolução do desempenho em relação aos clientes, serviços e produtos, à situação } \\
\text { financeira, ao mercado, às pessoas, aos fornecedores, aos processos e à sociedade. }\end{array}$ \\
\hline
\end{tabular}

Fonte: ANTP (2004). 
objetivo do mesmo é estimular as organizações de transporte e trânsito a adotarem modelos de gestão orientados para a excelência de desempenho de cada um dos seus processos e, em conseqüência, melhorarem a qualidade de seus serviços de forma contínua e sustentada. O Prêmio ANTP de Qualidade 2005 está estruturado em sete critérios, apresentados no Quadro 1 (ANTP, 2004).

O Prêmio ANTP de Qualidade pode servir de base para uma auto-avaliação das organizações, a partir de dimensões e parâmetros pré-estabelecidos. Desta forma, as organizações podem visualizar os pontos fortes e os pontos de melhoria e priorizar ações.

\subsection{Lean Management}

A proposta do Lean Management, segundo Jackson e Jones (1996), busca alinhar as estratégias da organização, e por meio de uma estrutura apropriada e do fortalecimento das forças competitivas, garantir a melhoria dos processos. Para tanto, os autores estabeleceram nove diretrizes, denominadas de áreas chaves, a serem estruturadas e desenvolvidas na busca de um sistema enxuto. O Quadro 2 apresenta os aspectos relativos a cada área chave segundo a proposta do Lean Management.

A efetiva implementação de um sistema enxuto necessita, segundo Jackson e Jones (1996), ser sustentada por elementos constitutivos baseados em gerenciamento interfuncional, trabalho em equipe, desenvolvimento organizacional e estratégias de curto e longo prazo. Henderson e Larco (2002) reforçam essa necessidade, salientando a importância dos gestores das organizações conhecerem as ferramentas apropriadas para cada situação e para o estágio de desenvolvimento da implementação do sistema enxuto.

\subsection{Mentalidade Enxuta}

A Mentalidade Enxuta, conforme apresentada por Womack e Jones (1998), é uma forma de especificar valor, alinhar na melhor forma a seqüência de ações que criam valor, realizar essas atividades sem interrupção toda vez que alguém as solicita e de modo cada vez mais eficaz. Os cinco princípios gerais da Mentalidade Enxuta são:

a) determinar precisamente o valor por produto especifico: Hines e Taylor (2000) e Schonberger

Quadro 2: Áreas chaves do Lean Management

\begin{tabular}{|c|c|}
\hline Área chave & Aspectos relativos à cada área chave \\
\hline 1. Foco no cliente & Alinha-se com a idéia de um nível zero de insatisfação dos clientes. \\
\hline 2. Liderança e estratégia & $\begin{array}{l}\text { É a capacidade do time gerencial de traduzir os requerimentos dos clientes em uma política con- } \\
\text { creta. }\end{array}$ \\
\hline 3. Organização enxuta & $\begin{array}{l}\text { A estrutura de interação entre diversos times e áreas requer que seja eliminada toda burocracia e } \\
\text { que se minimize o over-head. }\end{array}$ \\
\hline 4. Parcerias & $\begin{array}{l}\text { É o conjunto de relacionamentos baseado na confiança e que envolve empregados, fornecedores } \\
\text { e sociedade. }\end{array}$ \\
\hline $\begin{array}{l}\text { 5.Arquitetura da } \\
\text { informação }\end{array}$ & $\begin{array}{l}\text { Refere-se à estrutura de criação e distribuição de informações que dê suporte à estrutura organi- } \\
\text { zacional. }\end{array}$ \\
\hline 6.Cultura de melhoria & $\begin{array}{l}\text { Diz respeito à capacidade de times e indivíduos analisarem as defasagens em relação à estratégia e } \\
\text { problemas de qualidade para encontrar as causas raízes implementar as soluções efetivas. }\end{array}$ \\
\hline 7. Produção enxuta & Inclui a utilização de técnicas para a redução de perdas. \\
\hline 8. Manutenção enxuta & $\begin{array}{l}\text { Refere-se à abordagem da Manutenção Produtiva Total (TPM) que garante a eficiência, a precisão } \\
\text { e a facilidade na operação e na manutenção, assim como a disponibilidade de máquinas, equipa- } \\
\text { mentos e sistemas. }\end{array}$ \\
\hline 9. Engenharia enxuta & $\begin{array}{l}\text { Refere-se à prática da engenharia simultânea e todos os métodos necessários para o desenvolvi- } \\
\text { mento de novos produtos de forma rápida e consistente. }\end{array}$ \\
\hline
\end{tabular}

Fonte: Jackson e Jones (1996). 
(1990) salientam que o valor necessariamente deve ser determinado sob a perspectiva do cliente;

b) identificar a cadeia de valor: de acordo com Porter (1999), a reunião das atividades que são executadas para projetar, produzir, comercializar, entregar e sustentar seu produto compõe a cadeia de valor de uma empresa;

c) fazer o valor fluir sem interrupções: Rother \& Shook (1999) definem fluxo de valor como sendo toda a ação (agregando valor ou não) necessária para trazer um produto por todos os fluxos essenciais para sua produção;

d) adotar sistema de produção puxada: um processo inicial apenas deve produzir um bem ou serviço a partir da solicitação do processo posterior; em se tratando de organizações de serviços, Davis (2001) ressalta a importância de sincronizar a demanda e a capacidade; e,

e) buscar a perfeição: por meio de melhorias contínuas incrementais, conhecidas como kaizen, e por meio de melhorias radicais, conhecidas como kaikaku.

Uma vez apresentados os pilares teóricos sobre os quais se apoia a presente investigação, o próximo tópico tece considerações acerca dos elementos de cada abordagem, apropriados para o desenvolvimento desta investigação. Os mesmos serão a base para a estruturação do instrumento gerencial de avaliação do potencial de melhoria dos processos das organizações de transporte coletivo rodoviário urbano.

\subsection{Considerações acerca do referencial teórico}

Ao analisar criticamente as três abordagens que constituem o referencial teórico ao trabalho, procura-se identificar os elementos apropriados, em cada abordagem, que possam ser aplicados em organizações de transporte e que atendam os objetivos propostos. O Quadro 3 sintetiza os elementos de cada abordagem estudada.

Uma característica geral dos critérios de excelência e, portanto, do Prêmio ANTP de Qualidade 2005, é que os mesmos não prescrevem o uso de ferramentas específicas ou práticas de gestão vinculadas a cada critério, devendo a organização estabelecer as mais convenientes para sua estrutura e realidade. O foco principal é a verificação dos resultados decorrentes de toda ação sistêmica que venha ocorrer em todas as áreas. Não há uma ênfase específica na busca por sistemas enxutos, embora todos os crité- rios possam sustentar apropriadamente estratégias que possam ser estabelecidas para essa finalidade.

No que se refere à Mentalidade Enxuta, nenhuma referência é feita às questões estratégicas e à vantagem competitiva e nem como estas devem ser consideradas na definição de valor. Não se estabelecem nem citam-se mecanismos de medição de desempenho. $\mathrm{O}$ foco principal está na determinação do valor e na eliminação de atividades que não agregam valor segundo a percepção dos clientes.

A abordagem do Lean Management introduz elementos capazes de sustentar a implementação de sistemas enxutos, por meio da estratégia, da estrutura e das forças competitivas. Por outro lado, não menciona ou considera aspectos relativos aos resultados nem sugere ferramentas e técnicas possíveis para sua implementação.

Verifica-se, ao analisarem-se os parâmetros das três abordagens apresentadas, que Estratégia, Mensuração e Análise das Informações e Pessoas são referenciadas tanto no Lean Management como no Prêmio ANTP de Qualidade. Valor consta nas três abordagens, sendo que no Lean Management e no Prêmio ANTP apresenta-se como "foco no cliente". Fluxo de valor, citado nas três abordagens, consta no Lean Management como sendo "produção enxuta" e "organização enxuta". Sistema de valor, também nas três abordagens, é referenciado como "parceiros e fornecedores" no Lean Management e como "processos relativos aos fornecedores" no Prêmio ANTP. Produto/serviço está inserido no item "gestão de processos - projeto do produto" e referese à capacidade de a organização definir produtos/ serviços em função do valor definido pelo cliente. Produção puxada vincula-se à "engenharia enxuta" (relativo ao Lean Management) e aos "processos relativos aos serviços" (no Prêmio ANTP) e refere-se à capacidade da organização garantir um fluxo de serviço compatível com a demanda (Mentalidade Enxuta). Ações de melhoria é citada nas três abordagens. Resultados é mencionado no Prêmio ANTP, sendo o elemento de retro-alimentação para a alta direção reavaliar sistemicamente suas diretrizes e estratégias.

As três abordagens apresentadas podem ser consideradas complementares para os propósitos deste trabalho. O Quadro 4 sintetiza os parâmetros que constituirão a base teórica para a composição do instrumento gerencial de avaliação. Para efeitos de organização do trabalho, estes serão denominados de bases de análise.

O próximo item apresenta o delineamento da investigação e descreve o processo de seleção da amostra onde ocorrerão os estudos de caso. 
Quadro 3: Parâmetros do Prêmio ANTP de Qualidade 2005, da Mentalidade Enxuta e do Lean Management

\begin{tabular}{|c|c|c|}
\hline $\begin{array}{l}\text { Elementos da } \\
\text { Mentalidade Enxuta }\end{array}$ & $\begin{array}{l}\text { Elementos do "Lean } \\
\text { Management" }\end{array}$ & Elementos do Prêmio ANTP de Qualidade \\
\hline \multirow{8}{*}{ Valor } & \multirow{4}{*}{ Liderança e estratégia } & $\begin{array}{l}\text { 1. Liderança } \\
\text { 1.1 Liderança da alta administração } \\
\text { 1.2 Análise crítica desempenho global }\end{array}$ \\
\hline & & 2. Planejamento estratégico \\
\hline & & 2.1 Formulação das estratégias \\
\hline & & 2.2 Operacionalização das estratégias \\
\hline & \multirow{4}{*}{ Foco no cliente } & 3. Foco nos clientes e na sociedade \\
\hline & & 3.1 Conhecimento sobre os clientes e imagem da organização \\
\hline & & 3.2 Relacionamento com os clientes e medição de sua satisfação \\
\hline & & 3.3 Responsabilidade social \\
\hline & \multirow{3}{*}{ Arquitetura da informação } & 4. Mensuração, análise e gestão do conhecimento \\
\hline & & 4.1 Mensuração e análise do desempenho \\
\hline & & 4.2 Gestão da informação e do conhecimento \\
\hline & \multirow{4}{*}{$\begin{array}{l}\text { Cultura de melhoria (inclui } \\
\text { gestão de pessoas) }\end{array}$} & 5. Gestão de pessoas \\
\hline & & 5.1 Sistema de trabalho \\
\hline & & 5.2 Capacitação e desenvolvimento \\
\hline & & 5.3 Qualidade de vida \\
\hline Fluxo de valor & $\begin{array}{c}\text { Produção enxuta } \\
\text { Organização enxuta }\end{array}$ & $\begin{array}{l}\text { 6. Gestão de processos (projeto, produção de serviços e processos } \\
\text { de apoio) }\end{array}$ \\
\hline \multirow[t]{2}{*}{ Produção puxada } & Engenharia enxuta & 6.1 Processos relativos aos serviços \\
\hline & Manutenção enxuta & 6.2 Processos de apoio \\
\hline \multirow[t]{9}{*}{ Sistema de valor } & Parceiros e fornecedores & 6.3 Processos relativos aos fornecedores \\
\hline & & 6.4 Gestão econômico-financeira \\
\hline & & 7. Resultados \\
\hline & & 7.1 Relativos aos clientes e mercado \\
\hline & & 7.2 Relativos aos serviços \\
\hline & & 7.3 Econômico-financeiros \\
\hline & & 7.4 Relativos às pessoas \\
\hline & & 7.5 Relativos aos fornecedores \\
\hline & & 7.6 Relativos à sociedade \\
\hline Melhoria contínua & Cultura de melhoria & * ciclo de melhoria: inserido em diversos critérios. \\
\hline
\end{tabular}

Quadro 4: Bases de análise para a composição do instrumento de avaliação

\begin{tabular}{|l|l|}
\hline \multicolumn{1}{|c|}{ Bases de análise } & \multicolumn{1}{c|}{ Referências } \\
\hline Estratégia & Lean Management; Prêmio ANTP \\
\hline Valor & Lean Management; Prêmio ANTP; Mentalidade Enxuta \\
\hline Sistema de valor & Lean Management; Prêmio ANTP; Mentalidade Enxuta \\
\hline Produto/serviço & Lean Management; Prêmio ANTP \\
\hline Fluxo de valor & Lean Management; Prêmio ANTP; Mentalidade Enxuta \\
\hline Produção puxada & Lean Management; Prêmio ANTP; Mentalidade Enxuta \\
\hline Pessoas & Lean Management; Prêmio ANTP \\
\hline Mensuração e análise das informações & Lean Management; Prêmio ANTP \\
\hline Resultados & Prêmio ANTP \\
\hline Ações de melhoria & Lean Management; Prêmio ANTP; Mentalidade Enxuta \\
\hline
\end{tabular}




\section{DELINEAMENTO DA INVESTIGAÇÃO}

Esta pesquisa caracteriza-se por uma abordagem predominantemente qualitativa. Envolve a obtenção de dados descritivos de modo a compreender os fenômenos segundo a perspectiva dos participantes da situação em estudo, para então, sustentado por teorias e princípios convergentes com a busca da melhoria dos processos, identificar as lacunas nas práticas das organizações e os parâmetros considerados relevantes pelas mesmas.

O estudo de caso é a estratégia de pesquisa escolhida. De acordo com Yin (2001) e Voss et al. (2002) é a técnica de pesquisa a ser utilizada quando objetiva-se compreender "como" as empresas se posicionam em relação à implementação de cada um dos elementos a serem avaliados a partir de instrumento de diagnóstico construído para esta finalidade.

A unidade de análise é composta por três empresas de Porto Alegre - RS selecionadas com base em uma pesquisa exploratória anterior, publicada por Sellitto et al. (2003). Nesta pesquisa, todas as quinze empresas de transporte coletivo rodoviário urbano foram classificadas conforme sua capacidade de compreensão dos princípios da Mentalidade Enxuta e conceitos correlacionados, como os relativos a Sistemas da Qualidade, a Gestão de Processos e a Estratégia.

Optou-se, neste estudo, por trabalhar com empresas classificadas no primeiro grupo (composto de seis empresas), ou seja, aquelas cujos gestores conhecem os conceitos relativos aos sistemas enxuto e qualidade, a fim de minimizar o erro decorrente de problemas de interpretação e compreensão de conceitos utilizados no instrumento de diagnóstico.

Três, dentre as seis empresas do primeiro grupo, aceitaram participar desta pesquisa. As mesmas foram denominadas de "A", "B" e "C". As empresas "A", "B" e "C" pertencem a consórcios diferentes. A empresa "A" possui cerca de 200 veículos; a empresa "B" tem 90 veículos e a empresa " $C$ " tem cerca de 300 veículos; as empresas "B" e "C" possuem certificação ISO 9000:2000.

O método de trabalho estabelecido para a realização da pesquisa constou das seguintes fases: (i) o desenvolvimento do referencial teórico, considerando as abordagens selecionadas e a estrutura do transporte coletivo rodoviário urbano de Porto Alegre; (ii) o desenvolvimento do instrumento de diagnóstico a ser utilizado nos estudos de caso; o mesmo foi avaliado por três especialistas das áreas de transporte e sistemas enxutos e após, submetido a um teste piloto, para, então, gerar a sua construção final; (iii) aplicação do instrumento de diagnóstico nas empresas; e (iv) consolidação das informações coletadas e análise dos resultados obtidos.
Quanto ao método de aplicação do instrumento de diagnóstico, as empresas indicaram as pessoas aptas para responderem o mesmo. Foi preparado um roteiro para a entrevista, que incluía a aplicação do instrumento além de visitas ao local para observação direta.

Esta pesquisa delimita-se a investigar aspectos relativos às empresas de transporte e não estende os resultados para demais organizações que formam a cadeia de valor do sistema de transporte. Este estudo não permite generalizações para as demais empresas de Porto Alegre visto que os resultados obtidos relatam a situação das três organizações previamente selecionadas e com um grau de aplicação e compreensão dos itens a serem avaliados; esta não é a realidade das quinze empresas de Porto Alegre, conforme Sellitto et al. (2003).

\section{ELABORAÇÃO DO INSTRUMENTO DE DIAGNÓSTICO}

O instrumento de diagnóstico propõe-se a identificar quais elementos são, segundo a percepção das empresas, os mais relevantes para a melhoria dos processos e em que grau os mesmos estão sendo utilizados. Também servirá de guia para as entrevistas e a coleta de outras informações fornecidas pelos entrevistados.

Para facilitar a organização dos dados a serem coletados, cada uma das bases de análise foi desdobrada em pontos chave e cada ponto chave foi desdobrado em ponto de análise. Associaram-se aos mesmos, um conjunto de questões para verificar o grau de importância e de aplicação de cada parâmetro e conduzir a entrevista para a busca de informações mais detalhadas sobre "o que" e "como" a empresa procede em diversas situações. Os parâmetros a serem avaliados em cada base de análise são apresentados no Quadro 5.

Para cada questão foram associadas duas escalas Likert, com valores de 1 a 5 . A primeira escala corresponde ao grau de importância que a organização atribui para cada questão do ponto de análise e a segunda corresponde ao atual estágio de implementação de cada item. A relação entre os atributos qualitativos e os valores numéricos da escala Likert foi adaptada da Tabela de Critérios do Prêmio ANTP de Qualidade 2005 (ANTP, 2004) e é apresentada no Quadro 6. Para cada questão, serão anotadas todas as justificativas dos respondentes para cada valor atribuído, o que é, possivelmente o ponto mais rico da pesquisa em termos de coleta de informações.

O próximo tópico descreve os resultados obtidos a partir da aplicação do instrumento de diagnóstico nas três empresas da amostra. 
Quadro 5: Parâmetros de avaliação em cada base de análise

\begin{tabular}{|c|c|c|c|}
\hline $\begin{array}{l}\text { Bases de } \\
\text { análise }\end{array}$ & Pontos chaves & Pontos de análise & Parâmetros a serem avaliados \\
\hline \multirow{6}{*}{ Estratégia } & \multirow{3}{*}{$\begin{array}{l}\text { 1. Formulação da } \\
\text { estratégia }\end{array}$} & 1.1. Desdobrar planos de ação & \multirow{6}{*}{ Capacidade de gerar os resultados esperados. } \\
\hline & & 1.2. Balancear das necessidades & \\
\hline & & 1.3. Comunicar das estratégias & \\
\hline & \multirow{2}{*}{ 2. Liderança } & 2.1. Disseminar valores da empresa & \\
\hline & & 2.2. Anslisar desempenho global & \\
\hline & 3. Proposição valor & 3.1. Proposição de valor da empresa & \\
\hline \multirow{4}{*}{ Valor } & \multirow{2}{*}{ 4. Cliente } & 4.1. Características dos clientes & \multirow{4}{*}{$\begin{array}{l}\text { Capacidade de conhecer características dos clien- } \\
\text { tes e como estes percebem o valor do serviço ofe- } \\
\text { recido. }\end{array}$} \\
\hline & & 4.2. Percepção de valor pelo cliente & \\
\hline & \multirow{2}{*}{ 5. Mercado } & 5.1. Mercado atual & \\
\hline & & 5.2. Mercado potencial & \\
\hline \multirow{4}{*}{$\begin{array}{l}\text { Sistema de } \\
\quad \text { Valor }\end{array}$} & $\begin{array}{l}\text { 6. Cadeia de valor } \\
\text { (interna) }\end{array}$ & 6.1. Conhecimento do cliente interno & \multirow{4}{*}{$\begin{array}{l}\text { Capacidade de integrar a cadeia de valor e demais } \\
\text { parceiros na busca de objetivos comuns baseados } \\
\text { no valor definido pelo cliente. }\end{array}$} \\
\hline & \multirow{3}{*}{ 7. Parceiros } & 7.1. Fornecedores & \\
\hline & & 7.2. Consórcio & \\
\hline & & 7.3. Órgão gestor & \\
\hline \multirow{3}{*}{$\begin{array}{l}\text { Produto / } \\
\text { serviço }\end{array}$} & \multirow{2}{*}{$\begin{array}{l}\text { 8. Projeto do pro- } \\
\text { duto }\end{array}$} & 8.1. Projeto de equipamentos (ônibus) & \multirow{3}{*}{$\begin{array}{l}\text { Capacidade de garantir que produtos e serviços } \\
\text { foram concebidos com base no valor percebido } \\
\text { pelo cliente e que as operações são executadas } \\
\text { para garantir os resultados esperados. }\end{array}$} \\
\hline & & 8.2. Projeto do serviço & \\
\hline & 9. Serviço & 9.1. Serviço & \\
\hline \multirow{6}{*}{$\begin{array}{l}\text { Fluxo de } \\
\text { valor }\end{array}$} & \multirow{2}{*}{$\begin{array}{l}\text { 10. Processo em } \\
\text { geral } \\
\end{array}$} & 10.1. Organização dos processos & \multirow{6}{*}{$\begin{array}{l}\text { Capacidade de garantir que o valor flua ao lon- } \\
\text { go de todas as etapas da cadeia de valor, mini- } \\
\text { mizando/eliminando tudo que não agrega valor. } \\
\text { Garantir que os processos são apropriados para } \\
\text { atender os requisitos de projeto. }\end{array}$} \\
\hline & & 10.2. Eliminar perdas & \\
\hline & \multirow{3}{*}{$\begin{array}{l}\text { 11. Processo de } \\
\text { apoio }\end{array}$} & 11.1. Manutenção & \\
\hline & & 11.2. Materiais & \\
\hline & & 11.3. Administração & \\
\hline & 12. Processo direto & 12.1. Operações de serviço & \\
\hline \multirow{3}{*}{$\begin{array}{l}\text { Produção } \\
\text { puxada }\end{array}$} & \multirow{3}{*}{$\begin{array}{l}\text { 13. Produção do } \\
\text { serviço }\end{array}$} & 13.1. Capacidade de produção & \multirow{3}{*}{$\begin{array}{l}\text { Garantir um fluxo de serviços compatível com a } \\
\text { demanda. }\end{array}$} \\
\hline & & 13.2. Balanceamento e fluxo & \\
\hline & & 13.3. Programação da produção & \\
\hline \multirow{2}{*}{ Pessoas } & \multirow{2}{*}{$\begin{array}{l}\text { 14. Gestão de } \\
\text { pessoas }\end{array}$} & 14.1. Capacitação & \multirow{2}{*}{$\begin{array}{l}\text { Capacidade de capacitar e motivar pessoas para } \\
\text { assegurar condições de implementar melhorias. }\end{array}$} \\
\hline & & 14.2. Motivação & \\
\hline \multirow{3}{*}{$\begin{array}{l}\text { Mensuração/ } \\
\text { Análise das } \\
\text { Informações }\end{array}$} & \multirow{2}{*}{ 15. Mensuração } & 15.1. Sistema de informações & \multirow{3}{*}{$\begin{array}{l}\text { Capacidade de selecionar, obter, usar e melhorar } \\
\text { as informações necessárias para apoiar os proces- } \\
\text { sos, estratégia e melhoria do desempenho. }\end{array}$} \\
\hline & & 15.2. Mensuração do desempenho & \\
\hline & 16. Análise & 16.1. Análise das informações & \\
\hline \multirow[t]{2}{*}{ Resultados } & \multirow[t]{2}{*}{ 17. Resultados } & $\begin{array}{l}\text { 17.1. Resultado operacional/estratégi- } \\
\text { co }\end{array}$ & Capacidade de apresentar resultados, tendências, \\
\hline & & 17.2. Resultados comparativos & \\
\hline & 18. Melhorias & 18.1. Melhorias contínuas & Capacidade de estabelecer melhoria de forma sis- \\
\hline & & 18.2. Melhorias radicais & têmica. \\
\hline
\end{tabular}

Quadro 6: Relação entre atributos qualitativos e valores numéricos do grau de importância e de aplicação

\begin{tabular}{|l|l|}
\hline \multicolumn{1}{|c|}{ Escala para graus de importância } & \multicolumn{1}{c|}{ Escala para graus de aplicação } \\
\hline 1. Parâmetro é completamente irrelevante & 1. Não aplica ou aplica de modo inadequado \\
\hline 2. Parâmetro tem pouca importância & 2. Já implementou em áreas isoladas mas não deu continuidade \\
\hline 3. Parâmetro tem importância média & 3. Implementa, porém não de forma sistêmica. \\
\hline 4. Parâmetro é muito importante & 4. Implementa em toda organização, mas precisa consolidar. \\
\hline 5. Parâmetro é extremamente importante & 5. Implementa de forma sistêmica e consolidada \\
\hline
\end{tabular}




\section{APLICAÇÃO E RESPOSTAS}

Para a base de análise "Estratégia", as questões relativas à formulação de estratégia e à liderança são consideradas muito importante ou extremamente importante pelos entrevistados das três organizações. No que se refere à proposição de valor, para duas organizações, esse aspecto é considerado extremamente importante; para uma das empresas, este parâmetro tem importância média, pois não há flexibilidade e possibilidade das empresas inovarem e gerarem novos produtos.

Na base de análise "Valor", duas empresas consideram muito importante ou extremamente importante conhecer as características gerais dos clientes, a finalidade com que usam o transporte e os fatores de decisão que levam os mesmos a optar pelo ônibus. Uma empresa avalia esses parâmetros como tendo uma importância média, pois opera com linhas de público de baixa renda que não tem outras opções de transporte. Mesmo assim, essa organização é a que mais ênfase dá a realização de pesquisas próprias, buscando identificar seu cliente e seus requisitos, o que denota sua atenção a esse parâmetro.

Nas questões relativas ao mercado atual, as empresas assinalaram que é extremamente importante mapeá-lo, bem como conhecer suas reais dimensões e as ameaças dos concorrentes, mesmo que de outros modais. Com relação ao mercado potencial, as empresas consideram o mesmo cada vez mais escasso.

Com respeito às respostas referentes a base de análise "Sistema de Valor", não há integração entre as empresas dos consórcios visando otimizar o uso de recursos. A comunicação com o Órgão Gestor e as empresas, segundo os entrevistados, perde parte de sua eficiência pois é feita através do consórcio. A velocidade de atuação deixa a desejar e o foco está voltado para o cumprimento de horários. Os consórcios têm uma atuação mais ampla no que se refere à operação do sistema de transporte.

Na base de análise "Produto/serviço", as empresas " $\mathrm{B}$ " e "C" consideram relevante desenvolver novos serviços e atuam ativamente para propor novas linhas junto ao Órgão Gestor, acompanhar sua implantação e efetuar ajustes no nível de serviço oferecido. Segundo os entrevistados, os parâmetros relacionados ao serviço, na percepção do cliente, são mais relevantes que os relativos aos equipamentos (ônibus). As dificuldades de atendimento aos requisitos desta base de análise estão relacionadas à interação da cadeia de valor e as formas de garantir e medir a fidelidade dos clientes.

Na base de análise "Fluxo de valor", com relação aos processos de apoio e aos processos em geral, as três organizações consideram muito importante ou extremamente importante terem as rotinas de trabalho e procedimentos definidos e difundidos, identificar, tipificar, eliminar, quantificar e mudar os processos. Na empresa " $A$ ", segundo o entrevistado, nem sempre a qualidade tem sido visto como responsabilidade dos próprios executores.

A efetiva implementação de rotinas para melhoria dos processos mostrou-se aquém da importância atribuída, nas três organizações. A empresa " $A$ " considera que ainda não trabalha de forma sistêmica e que não tem focado a eliminação das perdas. A empresa " $C$ " também não vem priorizando a eliminação das perdas. A empresa "B" atua parcialmente na eliminação das perdas. As empresas " $A$ " e "B" citaram que a prioridade da eliminação das perdas não é maior em função da metodologia utilizada para o cálculo de tarifa (com base nos custos declarados pelas empresas).

No que se refere aos processos diretos (operações de transporte propriamente ditas), as empresas consideram que todos os parâmetros são muito importantes ou extremamente importantes. Todas as empresas trabalham com ônibus "reserva", mas o entrevistado da empresa "B" salientou que poderia haver um estudo mais detalhado para definir a proporção ótima de veículos necessários sem comprometer o serviço (acredita que os números são superestimados).

Para a base de análise "Produção Puxada", as três organizações consideram todos os aspectos extremamente importantes. Os entrevistados relataram, quanto à aplicação, que possivelmente existe uma capacidade instalada suficiente ou até maior que a demanda atual e sugerem um estudo mais efetivo sobre a demanda real e o tamanho de frota ideal para esta demanda. A demanda real e suas variações ao longo do dia, mês e ano poderiam ser melhor mapeadas a fim de se estabelecer a capacidade instalada para cada empresa.

As três organizações consideram muito importantes ou extremamente importantes os parâmetros relacionados a base de análise "Pessoas". A aplicação vem ocorrendo de modo sistêmico e as empresas têm práticas como grupos de CCQ (Círculos de Controle da Qualidade), reconhecimento de esforços adicionais ou em grupo, precisando, nas empresas "A" e "C" consolidar ainda mais essa aplicação.

Com relação aos resultados obtidos na base de análise "Mensuração e Análise das Informações", os parâmetros relacionados aos sistemas de informações, à mensuração do desempenho e a análise das informações foram considerados muito importantes ou extremamente importantes pelos entrevistados das três organizações. As empresas " $\mathrm{B}$ " e "C" precisam aprimorar o sistema de informações de modo a garantir a interação dos dados provenientes de todas 
as áreas e processos. As organizações efetuam análise de desempenho dos processos e da organização e estabelecendo planos de ações quando necessário.

Para a base de análise "Resultados", as questões referentes aos Resultados Operacionais e Estratégicos e Resultados Comparativos foram considerados muito importantes ou extremamente importantes pelas três organizações. A empresa " $A$ " precisa sistematizar a análise de seus resultados, principalmente no que se refere aos indicadores relativos aos clientes; esse problema decorre da dificuldade de conhecer plenamente os clientes e suas necessidades. As empresas " $B$ " e " $C$ " buscam suprir essa dificuldade com pesquisas próprias.

Em relação a base de análise "Ações de Melhoria", as três organizações consideram muito importante ou extremamente importante a implementação sistêmica de ações de melhorias. A empresa "A" já deu mais ênfase, anteriormente, à utilização sistêmica de ferramentas da qualidade. As empresas "B" e "C" vêm aplicando e estimulando o uso destas ferramentas de modo coordenado e estruturado. Com relação às "Melhorias Radicais", as empresas "A" e "B" consideram extremamente importante existirem condições administrativas, de liderança e físicas para efetivar tais mudanças, embora a empresa " $\mathrm{A}$ " não se considere preparada para tal. A empresa " $\mathrm{C}$ " não considera essa possibilidade frente à situação do transporte e o histórico da empresa.

\section{DISCUSSÃO DOS RESULTADOS}

$\mathrm{Na}$ seqüência, discutem-se os resultados auferidos com a aplicação do instrumento de diagnóstico. A Figura 2 demonstra, por meio de gráficos tipo Radar, uma síntese dos valores numéricos atribuídos pelas empresas para cada base de análise, obtidos a partir da média das notas de cada questão. Procura-se visualizar, desta forma, o potencial de melhorias em relação ao que as empresas consideram relevante para a melhoria dos seus processos e ao que elas efetivamente fazem. Salienta-se que os valores numéricos desta síntese devem ser analisados conjuntamente com a descrição dos dados e fatos apresentados pelos entrevistados.

A empresa "A" é a que apresenta maior defasagem entre o que acredita ser importante para a melhoria dos processos e o que efetivamente aplica. O elemento "Valor" é o que apresenta a maior lacuna. Essa defasagem ocorre, segundo o entrevistado, pois a empresa, em alguns parâmetros, limita-se a atender os requisitos estabelecidos pelo Órgão Gestor.

A empresa "B" é uma organização que busca suprir as lacunas entre o que percebe em relação ao que necessita e o que aplica. Nas bases de análise
"Estratégia", "Valor" e "Resultados", os graus de aplicação atribuídos são maiores que os graus de importância. A organização efetiva algumas ações que, segundo o entrevistado, excedem o necessário no momento atual, mas preparam a empresa para situações futuras.

A empresa "C" vem procurando atender os requisitos dos critérios de excelência do Prêmio ANTP. Reconhece que sua estratégia não está focada diretamente para a eliminação dos desperdícios. A base de análise "Sistema de valor" apresenta a maior lacuna entre grau de importância e de aplicação devido a dificuldade de administrar os estoques e desenvolver parceiras de médio e longo prazo com fornecedores.

Nas três empresas, a base de análise "Produção puxada" é a que apresenta menor defasagem entre os graus de importância e de aplicação. Na percepção dos entrevistados existe sobra de capacidade instalada frente à atual demanda. Isso caracteriza, segundo os pressupostos de sistema enxuto, uma perda.

Graus de importância e aplicação - Empresa "A"

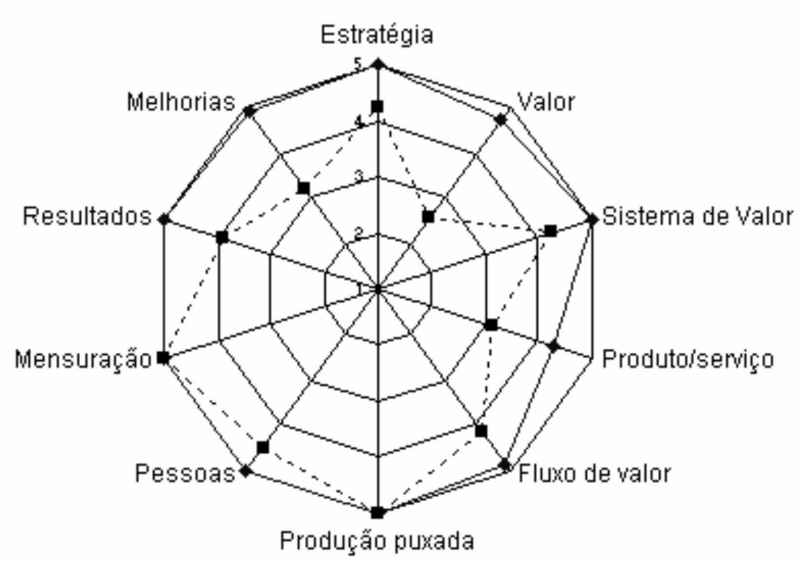

Graus de importância e de aplicação - Empresa "B"

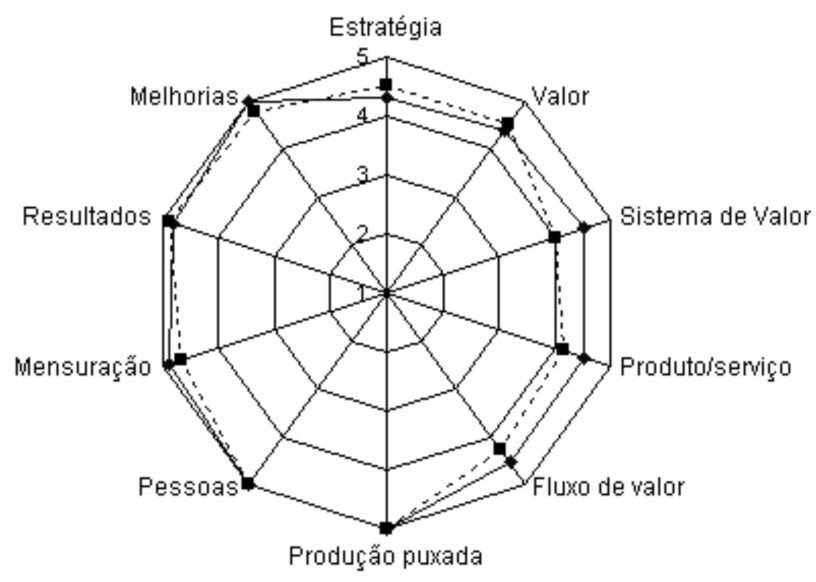

Figura 2: Graus de importância e de aplicação 


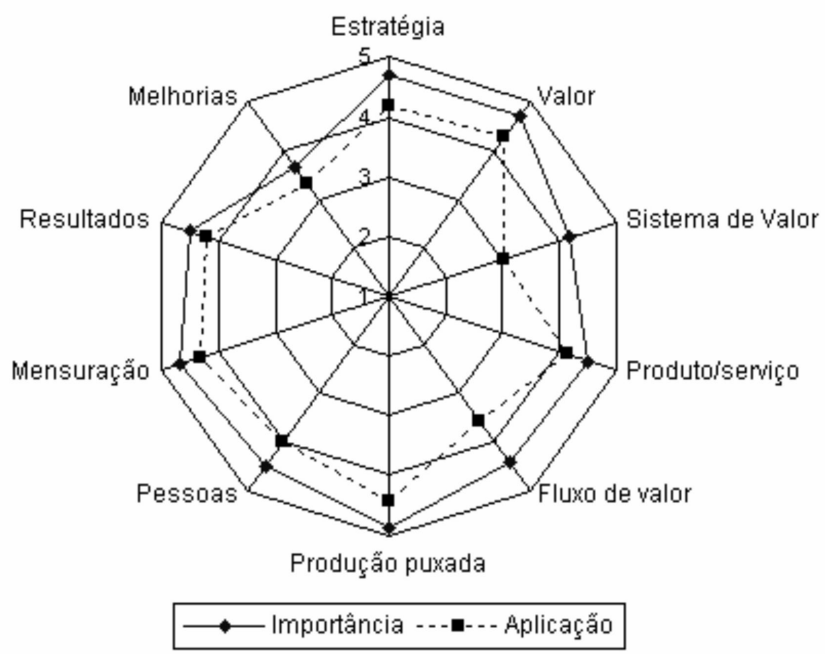

Figura 2: Graus de importância e de aplicação

Salienta-se, também, que as organizações estudadas e a ATP-POA (Associação dos Transportadores de Passageiros de Porto Alegre) declararam estar cientes da necessidade de reverter o quadro de perda de passageiros e de propor um serviço apropriado às necessidades da sociedade, sob o risco terem sérios problemas de sustentabilidade futura.

Por outro lado, também foi mencionado, por entrevistados de duas organizações, que o atual sistema de determinação da remuneração do serviço de transporte a ser pago pelo serviço de transporte prestado pode ser um fator limitante para a busca de melhorias nos processos e pode gerar um paradoxo em relação à melhoria do sistema como um todo. Exemplificabdo esse contrasenso, um dos entrvistados declarou que pode ser vantajoso uma organização manter uma frota maior que a necessária, uma vez que isso implica em aumento do patrimônio da empresa e o cálculo da remuneração do serviço de transporte a ser pago.

Apresentam-se, na seqüência, as considerações finais acerca deste trabalho e propostas de continuidade da pesquisa.

\section{CONSIDERAÇÕES FINAIS E CONTINUIDADE DE PESQUISA}

A partir do referencial teórico estabelecido foi possível elaborar um instrumento de avaliação específico para as empresas de transporte de Porto Alegre, considerando termos teóricos e princípios convergentes para a busca da melhoria dos processos. Desta forma, o objetivo desta pesquisa de identificar o potencial de melhoria dos processos das empresas foi alcançado. As lacunas entre o grau de importância e de aplicação de cada parâmetro avaliado indicam os pontos de maior defasagem entre parâmetros relevantes para as empresas estudadas.

Destaca-se a fragilidade no conhecimento do cliente e de suas necessidades por parte de uma das empresas; esse ponto é que deve direcionar a proposição de valor da empresa e guiar ações específicas para agregar valor ao serviço oferecido. $\mathrm{O}$ sistema de valor é outro parâmetro que apresentou maior defasagem; indica necessidade de ações conjuntas, em toda cadeia de valor.

Como proposta para continuidade desta pesquisa, sugere-se mapear todas as empresas da região, identificando perfil geral do setor. Desta forma, será possível propor ações específicas e diretrizes válidas para o segmento e a região. Um mapeamento das práticas e ferramentas que contribuem para a eliminação de perdas e otimização do uso de recursos, já utilizadas pelas empresas, poderá ser efetuado. Deste modo, pode-se compilar essas informações e sugerir um conjunto de técnicas, práticas e ferramentas capazes de contribuir para tornar as empresas de transporte "enxutas".

Um estudo sobre o compartilhamento de recursos das empresas de mesmo consórcio é sugerido, eis que foram identificados indícios de que pode ser vantajoso para as organizações da mesma bacia geográfica a divisão de veículos reserva, instalações, recursos de manutenção, estoques de peças de reposição, etc.

Por fim, agradecemos a Profa. Dra. Ana Maria Volkmer Azambuja (FURG), ao Sr. Jorge Roni Martins (consultor na área de transportes coletivos) e Gustavo Simionovisky (ATP - POA) pelas contribuições durante a elaboração do instrumento de diagnóstico. Igualmente agradecemos às três empresas participantes pela atenção e disponibilização de informações.

\section{REFERÊNCIAS BIBLIOGRÁFICAS}

Antunes, Jr. J. A. (1998) Em direção a uma teoria geral do processo na administração da produção: uma discussão sobre a possibilidade de unificação da Teoria das Restrições e da teoria que sustenta a construção dos sistemas de produção com estoque zero. Tese (Doutorado em Administração de Empresas) - PPGA, UFRGS, Porto Alegre.

ASSOCIAÇÃO NACIONAL DE TRANSPORTES PÚBLICOS - ANTP (1999) Transporte Humano - cidades com qualidade de vida. São Paulo : ANTP.

ASSOCIAÇÃO NACIONAL DE TRANSPORTES PÚBLICOS - ANTP (2004) Prêmio ANTP de Qualidade 2005. São Paulo: ANTP. Disponível em: $<$ http://www.antp.org.br $>$. Acesso em 02 jun. 2004. 
Azambuja, A. M. W. (2002) Análise de eficiência na gestão do transporte urbano por ônibus em municípios brasileiros. Tese (Doutorado em Engenharia de Produção) - PPGEP, UFSC, Florianópolis.

Ballard, G. (2003) Key differences between lean construction and current forms of project management. Disponível em: $<$ http://www.leanconstruction.org > . Acesso em 16 nov. 2003.

Borchardt, M. (2005) Diretrizes para a implementação dos princípios da Mentalidade Enxuta: o caso das empresas de transporte coletivo rodoviário urbano. Tese (Doutorado em Engenharia de Produção) - PPGEP, UFSC, Florianópolis.

Cerra, A. e Bonadio, P. (2000) As relações entre estratégia de produção, TQM e JIT - estudos de caso em uma empresa do setor automobilístico e em dois de seus fornecedores - Revista Gestão e Produção - v. 7, n. 3, p. 305-320.

Costa, M.; Lindau L. A.; Sousa, F.; Fogliatto, F. (2001) Estudo comparativo entre empresas de ônibus utilizando AHP: o caso das empresas consorciadas de Porto Alegre. In: Lima J. \& Setti, J. (org). Panorama Nacional da Pesquisa em Transportes. v. 2, p. 135-142.

Cunningham, L.; Young, C.; Lee, M. (2000) Methodological triangulation in measuring public transportation service quality. Transportation Journal. v. 40, N. 1, p. 35-48.

Cypriani, I. e Guedes C. (2002) A importância dos sistemas de informação sobre usuários na qualidade do serviço de transporte coletivo urbano. Revista dos Transportes Públicos/ ANTP - v. 25, no. 97, p. 63-78.

Davis, M. (2001) Fundamentos da Administração da Produção. Porto Alegre : Ed. Bookman.

EPTC (2004). Empresa Pública de Transporte e Circulação de Porto Alegre - RS. Disponível em <http://www.eptc.com.br>. Acesso em 02 jun. 2004.

Fullerton, R.; McWatters, C. e Fawson, C. (2003) An examination of the relationship between JIT and financial performance. Journal of Operations Management. v. 21, p. 383 - 404.

Henderson, B. e Larco, J. (2002) Lean Transformation: how to change your business into a lean enterprise. Richmond: The Oaklea Press.

Hines, P. e Taylor, D. (2000) Enxugando a empresa: um guia para implementação. São Paulo: IMAM.

Jackson, T. e Jones, K. Implementing a lean management system. Portland: Productivity Press, 1996.

Johnston, R.; Fitzgerald, L.; Markou, E. e Bringnau, S. (2001) Target setting for evolutionary and revolutionary process change. International Journal of Operations \& Production Management. v. 21, n. 11, p. 1387-1403.

Kaynak, H. (2003) The relationship between total quality management practices and their effects on firm performance. Journal of Operations Management. v. 21, p. 405-435.

Macario, R. (2000) Upgrading quality in urban mobility systems. Total Quality Management. v. 11, n. 4 - 6; p. 747-753.

Nilsson, L.; Johnson, M. e Gustafsson, A. (2001) The impact of quality practices on customer satisfaction and business results: product versus service organizations. Journal of Quality Management. v. 6, 4th, p. 5-27.
NTU - ASSOCIAÇÃO NACIONAL DAS EMPRESAS DE TRANSPORTES URBANOS. (2004) Desoneração dos custos e barateamento das tarifas do transporte público. Disponível em: <http://www.ntu.org.br/frame_publicacoes.htm>. Acesso em 27 mar. 2005.

Porter, M. (1999) Vantagem competitiva: criando e sustentando um desempenho superior. Rio de Janeiro: Campus.

Rother, M. e Shook, J. (1999) Aprendendo a enxergar: mapeando o fluxo de valor para agregar valor e eliminar o desperdício. São Paulo: Lean Institute Brasil.

Sánchez, A. e Pérez, M. (2001) Lean indicators and manufacturing strategies. International Journal of Operations \& Production Management. v. 21, n. 11, p. 1433-1451.

Shah, R. e Ward, P. (2003) Lean manufacturing: context, practice bundles and performance. Journal of Operations Management. v. 21, p. 129-149.

Schonberger, R. (1990) Building a chain of customer. New York : The Free Press.

Sellitto, M., Borchardt, M. e Pereira, G. (2003) Assessing the degree of promptness of a service industry to adopt lean thinking. Revista Eletrônica de Administração - Management of Organizations. v. 9, n. 6, p. 105-130.

STS (2004) Sistema Transportador Sul. Disponível em <http:// www.sts.com.br>. Acesso em 02 jun. 2004.

Voss, C.; Tsikriktsis, N. e Frohlich, M. (2002) Case research in operations management. International Journal of Operations \& Production Management. v. 22, n. 2, p. 195-219.

Womack, J.e Jones, D. (1998) A Mentalidade enxuta nas empresas: elimine o desperdício e crie riquezas. Rio de Janeiro: Campus.

Yin, R. (2001) Estudo de caso: planejamento e método. Porto Alegre: Bookman, 2001.

Miriam Borchardt (miriamb@unisinos.br) Giancarlo Medeiros Pereira (gian@unisinos.br) Antônio Sérgio Coelho (coelho@deps. ufsc.br) Artigo recebido em 17/10/2005 e aprovado em 28/04/2006. 